\title{
Validity and Reliability of the Modified Manchester Health Questionnaire in Assessing Patients With Fecal Incontinence
}

\author{
Soo Kwon, M.D., ${ }^{1}$ Anthony G. Visco, M.D., ${ }^{1}$ Mary P. Fitzgerald, M.D., ${ }^{2}$ \\ Wen Ye, M.S., ${ }^{3}$ William E. Whitehead, Ph.D., ${ }^{4}$ for the Pelvic Floor Disorders \\ Network (PFDN) \\ ${ }^{1}$ Division of Female Pelvic Medicine and Reconstructive Surgery, University of North Carolina at \\ Chapel Hill, Chapel Hill, North Carolina \\ ${ }^{2}$ Division of Female Pelvic Medicine and Reconstructive Surgery, Loyola University, Maywood, Illinois \\ ${ }^{3}$ Pelvic Floor Disorders Network Data Coordinating Center, University of Michigan, Ann Arbor, Michigan \\ ${ }^{4}$ Division of Gastroenterology and Hepatology, University of North Carolina at Chapel Hill, Chapel Hill, \\ North Carolina
}

PURPOSE: To date, no measures of fecal incontinence severity or its impact on quality of life have been validated for telephone interview. This study was designed to 1) compare responses of a self-administered and a telephoneadministered Fecal Incontinence Severity Index; 2) compare a self-administered Fecal Incontinence Quality of Life Scale to the Manchester Health Questionnaire after modifying the latter for telephone administration and American English (Modified Manchester Health Questionnaire); 3) assess test-retest reliability of the telephone-administered Modified Manchester Health Questionnaire; and 4) assess

Supported by Pelvic Floor Disorders Network.

Supported by NICHD grants U10 HD41249, U10 HD41268, U10 HD41248, U10 HD41250, U10 HD41261, U10 HD41263, U10 HD41269, U10 HD41267.

Presented at the American Urogynecologic Society, Hollywood, Florida, September 11 to 13, 2003.

Reprints are not available.

Correspondence to: William E. Whitehead, Ph.D., Division of Gastroenterology and Hepatology, University of North Carolina at Chapel Hill, CB\# 7080, Bioinformatics Building, Room 1140F, Chapel Hill, North Carolina 27599-7080, e-mail: william whitehead@med.unc.edu

Dis Colon Rectum 2005; 48: 323-334

DOI: $10.1007 /$ s10350-004-0899-y

(c) The American Society of Colon and Rectal Surgeons

Published online: 21 December 2004 the internal consistency of the Modified Manchester Health Questionnaire subscales. METHODS: Consecutive, Englishspeaking, nonpregnant females known to have fecal incontinence were invited to participate. Two validated paper questionnaires accompanied the letter informing them of the study: Fecal Incontinence Severity Index and Fecal Incontinence Quality of Life Scale. Consenting patients were contacted for the initial telephone administration of the Modified Manchester Health Questionnaire, and patients who agreed to continue the study were contacted for a repeat telephone administration of the Modified Manchester Health Questionnaire two to four weeks after completing the first interview. RESULTS: Fifty-one females were invited to participate in the study; however, 13 declined or were ineligible. Thirty females, aged $49.3 \pm 10.3$ years, returned self-administered questionnaires and completed the first telephone interview, and 21 completed a second telephone interview after an average interval of 23 days. The telephone-administered Fecal Incontinence Severity Index scores were significantly lower than those yielded by the self-administered Fecal Incontinence Severity Index, (6.19 vs. 9.85; $P<0.001)$, but the telephone and written administrations were significantly correlated $(r=0.5 ; P<0.02)$. Correlations between the Modified Manchester Health Questionnaire quality of life subscales and the paper Fecal Incontinence Quality of Life subscales ranged from 0.6 to 0.9 (median, $r=0.81$ ). The correlation between the total score for the Fecal Incontinence Quality of Life and the total score for the Modified Manchester Health Questionnaire quality of life scales was $0.93(P<0.001)$. Test-retest reli- 
Table 1.

Study Design

\begin{tabular}{|c|c|c|}
\hline $\begin{array}{c}\text { Telephone-Administered } \\
\text { FISI }\end{array}$ & Validation & $\begin{array}{l}\text { Self-Administered } \\
\text { FISI }\end{array}$ \\
\hline $\begin{array}{c}\text { Telephone-Administered } \\
\text { MMHQ }\end{array}$ & Validation & $\begin{array}{l}\text { Self-Administered } \\
\text { FIQOL }\end{array}$ \\
\hline $\begin{array}{c}1^{\text {st }} \text { Telephone-Administered } \\
\text { FISI }\end{array}$ & Reliability & $\begin{array}{c}2^{\text {nd }} \text { Telephone-Administered } \\
\text { FISI }\end{array}$ \\
\hline $\begin{array}{c}1^{\text {st }} \text { Telephone-Administered } \\
\text { MMHQ }\end{array}$ & Reliability & $\begin{array}{c}2^{\text {nd }} \text { Telephone-Administered } \\
\text { MMHQ }\end{array}$ \\
\hline
\end{tabular}

Internal Consistency

MMHQ Subscales

$\mathrm{FISI}=$ Fecal Incontinence Severity Index; MMHQ = Modified Manchester Health Questionnaire; FIQOL = Fecal Incontinence Quality of Life Questionnaire.

ability for the eight Modified Manchester Health Questionnaire subscales ranged from 0.55 to 0.98 (median, $r=0.83$ ), and test-retest reliability for the two telephone administrations of the Fecal Incontinence Severity Index was $r=0.75$. Cronbach's alpha for the eight Modified Manchester Health Questionnaire subscales ranged from 0.79 to 0.92 (median, alpha $=0.85$ ). CONCLUSIONS: Telephone-administered versions of the Modified Manchester Health Questionnaire showed good-to-excellent validity, internal consistency, and test-retest reliability. The telephone-administered Fecal Incontinence Severity Index yielded lower severity scores than the written Fecal Incontinence Severity Index; however, the difference (3.66 units) was not clinically significant. [Key words: Fecal incontinence; Health surveys; Health questionnaires; Quality of life; Validity; Reliability]

$\mathrm{F}$ ecal incontinence (FI) affects 1 to 17 percent of the female population, ${ }^{1,2}$ and 47 percent of those in nursing homes. ${ }^{3}$ Although FI is not life threatening, it often causes limitations in social, emotional, and physical functioning. The effect of FI on an individual's general well being is determined not only by the type and severity of symptoms, but also by the individual's psychosocial adjustment to those symptoms.

Several questionnaires describing both FI symptom severity ${ }^{4-7}$ and its effect on health-related quality of life $e^{8,9}$ have been developed and validated for clinical and research use. However, none of these was devel- oped and validated for telephone administration. The availability of a telephone-administered measure of fecal incontinence severity and health-related quality of life would reduce the cost of conducting clinical trials and would make it possible to perform epidemiologic surveys. We, therefore, developed a telephone-administered version of the Fecal Incontinence Severity Scale (FISI) ${ }^{7}$ and the Manchester Health Questionnaire (MHQ), ${ }^{9}$ which were combined into one interview as the Modified Manchester Health Questionnaire (MMHQ; see METHODS).

This study was designed to 1) compare the selfadministered FISI to the telephone-administered FISI; 2) compare the self-administered Fecal Incontinence Quality of Life Scale (FIQOL) ${ }^{8}$ to the telephoneadministered MMHQ quality of life scales; 3) assess test-retest reliability of the MMHQ and the telephoneadministered FISI; and 4) assess the internal consistency of the MMHQ subscales (Table 1).

\section{METHODS}

After approval by the Institutional Review Board for the Protection of Human Subjects in Research, we invited consecutive females to participate in this study 
who had been evaluated for fecal incontinence between July and September 2002 by the Division of Gastroenterology and Hepatology or the Division of Female Pelvic Medicine and Reconstructive Pelvic Surgery at the University of North Carolina at Chapel Hill. Adult females were included if they were English-speaking, nonpregnant, and known to have fecal incontinence based on a review of their medical records.

Instruments developed to measure the severity of fecal incontinence ${ }^{4-7}$ included questions about the frequency of incontinent episodes of various types (i.e., gas, liquid stool, mucus, and formed stool). Some also included questions on the use of pads or plugs, ${ }^{4,5}$ antidiarrheal medications, impact on quality of life, and association with a strong urge to defecate. ${ }^{4}$ Among published scales, the $\mathrm{FISI}^{7}$ is the only one that includes empirically derived weights to translate the frequency-by-consistency ratings into a clinically meaningful index of severity. Higher scores on the FISI represent greater severity of incontinence.

Two disease-specific quality of life instruments have been developed for fecal incontinence. The Fecal Incontinence Quality of Life scale ${ }^{8}$ includes 29 items that are grouped into four scales: lifestyle, coping behavior, depression and self-perception, and embarrassment. The alternative Manchester Health Questionnaire9 was developed in England by modifying questions on urinary incontinence from the King's Health Questionnaire. ${ }^{10}$ The MHQ contains 31 items that are grouped into 8 subscales: general health, incontinence impact, role, physical function, social function, personal function, emotional problems, sleep and energy, and severity. However, the severity subscale refers to lifestyle adaptations made by the patient in response to having fecal incontinence; it is distinct from the FISI, which measures severity in terms of the frequency of different types of incontinence: solid, liquid, mucus, and gas. For the MMHQ, higher scores reflect poorer quality of life, whereas for the FIQOL, higher scores represent better quality of life.

In developing a telephone interview to study the impact of fecal incontinence on quality of life, we chose the MHQ9 ${ }^{9}$ over the FIQOL, ${ }^{8}$ because the MHQ has a simple answer format that is easy to incorporate into an interview, whereas the FIQOL involves four different answer formats (i.e., frequency, degree of agreement, and two ordinal scales), which may complicate the construction of an easily understood interview. The answer format for the MHQ also is com- patible with the answer format of the FISI, making it easier to integrate both severity and quality of life questions into the same interview. Both the $\mathrm{MHQ}^{9}$ and FIQOL $^{8}$ have been validated and shown to be internally consistent and reliable on repeated assessment.

The MHQ includes a set of ten questions that are similar in content to the items on the FISI, e.g., "How often do your bowels leak when coughing or sneezing?" The developers of the MHQ refer to these ten questions as a "symptom scale," but they do not intend for this symptom scale to be scored. They state, "It is the intention of the authors that the symptom scale is always administered with the quality of life scale but that it is not scored. The symptom scale should act as a guide to help health professional build up a picture of the patient's condition, but the quality of life scale should be used to measure the severity of incontinence in terms of how it impacts on a female's health status." 9

Because the items on the MHQ symptom scale are similar to items on the FISI, if we asked questions from the FISI followed by questions from the MHQ, the patient might perceive the interview as redundant and confusing. We therefore merged the questions from the FISI with similar questions from the MHQ symptom scale. One question that was deleted from MHQ was "How would you describe your health at the present?" All the questions from FISI were included in the MMHQ. We also rephrased some of the MHQ questions to make them more consistent with American English. The resulting questionnaire is called the Modified Manchester Health Questionnaire. In the remainder of this article, we will distinguish between the telephone-administered FISI and the MMHQ quality of life scales (MMHQ-QOL), but both of these scales are incorporated into the MMHQ, which is given in the Appendix.

\section{Study Design}

Patients meeting inclusion criteria were sent a standard letter informing them of the study along with the two validated questionnaires: FISI $^{7}$ and FIQOL. ${ }^{8}$ The letter also provided a contact number if they decided not to participate. Two to three weeks after the mailing, consenting patients were contacted for the initial telephone administration of the MMHQ. In most cases, this followed receipt of their paper questionnaires. When we were unable to reach a patient by telephone, up to three telephone messages were left. 
Table 2.

Pearson Correlation Coefficients Comparing Self-Administered FIQOL With Telephone-Administered MMHQ-QOL

\begin{tabular}{lcccc}
\hline & \multicolumn{4}{c}{ FIQOL Subscales } \\
\cline { 2 - 5 } \multicolumn{1}{c}{ MMHQ Scales } & Depression Self-Perception & Embarrassment & Lifestyle & Coping Behavior \\
\hline Impact & 0.73 & 0.85 & 0.87 & 0.82 \\
Role & 0.65 & 0.79 & 0.83 & 0.76 \\
Physical & 0.68 & 0.83 & 0.85 & 0.76 \\
Social & 0.76 & 0.72 & 0.9 & 0.8 \\
Relationship & 0.46 & 0.43 & 0.35 & 0.6 \\
Emotion & 0.7 & 0.75 & 0.67 & 0.65 \\
Sleep and energy & 0.7 & 0.65 & 0.79 & 0.72 \\
Severity & 0.7 & 0.79 & 0.74 & 0.83 \\
\hline
\end{tabular}

FIQOL = Fecal Incontinence Quality of Life Questionnaire; MMHQ-QOL = Modified Manchester Health Questionnaire Quality of Life scales.

A second mailing was sent to those who did not respond to the first mailing. Approximately two to four weeks after the initial telephone interview, the patients who agreed to continue the study were contacted for a repeat telephone administration of the MMHQ. No treatment intervened between the first and second interview or between the written FISI and the first telephone interview.

\section{Data Analysis}

All completed forms were sent to the Pelvic Floor Disorders Network Data Coordinating Center for data entry and analysis. The paper FISI and the telephoneadministered FISI were scored using patient-derived weights. ${ }^{8}$ To assess the convergent validity of the MMHQ relative to the FIQOL, four FIQOL subscales (depression, embarrassment, lifestyle, and coping) were related to the eight subscales of the MMHQ by Pearson correlation coefficient. In addition, the first telephone-administered FISI was compared to the self-administered paper FISI by use of a paired Student's $t$-test. The test-retest reliability was assessed by the Pearson correlation coefficient and Cronbach's alpha was used to assess internal consistency of the MMHQ-QOL subscales.

\section{Sample Size}

We planned to collect data from 50 patients. With 50 patients, there is 80-percent power to identify a correlation of 0.4 when using a two-tailed 5-percent level of significance. Although 50 were approached, we obtained data from approximately 30 . With 30 patients, there is 80-percent power to identify a correlation of 0.5 . Also, with data from 30 patients instead of 50 patients, there is a 30-percent increase in the esti- mate of the standard error compared with 50 patients. Both of these changes did not impair the results of the validation study.

\section{RESULTS}

Of 51 females who were invited to participate in our study, 3 were determined to be ineligible: 1 patient spoke only Spanish, 1 was pregnant, and 1 had a diagnosis of constipation (i.e., she was inappropriately included in the sample); an additional 6 had incorrect telephone numbers, which could not be traced. Of 42 eligible patients, 5 declined and 7 agreed to participate by telephone but provided no data. The participation rate $(30$ who provided data of 42 eligible) was 71.4 percent. Participants were similar to eligible nonparticipants in average age $(49.3 \pm 10.3$ vs. $42.8 \pm 7.2$ years, respectively) and racial distribution (24 white, 4 black, 1 Hispanic, and 1 other in the eligible participant group vs. 10 white and 2 black in the eligible nonparticipant group). Although $30 \mathrm{fe}-$ males provided data, 2 did not return a questionnaire, 1 did not complete the first telephone interview, and 8 did not complete the second interview. The average test-retest interval was 23 (range, 14-41) days.

\section{Telephone Interview $v s$. Paper Questionnaire}

Telephone-administered FISI scores were significantly lower than self-administered FISI (mean \pm standard deviation, $6.19 \pm 3.09$ vs. $9.85 \pm 4.19$, $\mathrm{t}(20)=$ 4.23; $P<0.001)$. However, the telephoneadministered FISI scores were significantly correlated with a self-administered questionnaire FISI ( $r=0.5$; $P=0.02$ ). 
Table 3.

Correlations Between the First and Second Telephone Interviews and Internal Consistency of the MMHQ Subscales From the First Interview

\begin{tabular}{lcc}
\hline \multicolumn{1}{c}{ Scale } & $\begin{array}{c}\text { Reliability Coefficients: } \\
\text { Pearson Correlation } \\
\text { Coefficients Between } \\
\text { the Two Interviews }\end{array}$ & $\begin{array}{c}\text { Cronbach's } \\
\text { Alpha From } \\
\text { the First } \\
\text { Interview }\end{array}$ \\
\hline Impact & 0.88 & $\#$ \\
Role & 0.75 & 0.79 \\
Physical & 0.92 & 0.91 \\
Social & 0.98 & 0.92 \\
Relationship & 0.55 & 0.81 \\
Emotion & 0.77 & 0.87 \\
Sleep \& Energy & 0.83 & 0.85 \\
Severity & 0.95 & 0.83 \\
\hline
\end{tabular}

MMHQ = Modified Manchester Health Questionnaire.

\#Cronbach's alpha cannot be computed on a single item scale.

Table 2 shows the relationship of the selfadministered FIQOL to the scales from the first telephone administration of the MMHQ-QOL. The total score on the FIQOL and the total score on the MMHQ were highly correlated $(r=0.93 ; P<0.0001)$. Furthermore, all subscales of the FIQOL were correlated with all subscales of the MMHQ-QOL (Table 2); there were no unique associations among the subscales.

Table 3 shows the test-retest reliability coefficients for the subscales of the telephone-administered MMHQ-QOL. The median reliability coefficient was $r=0.85$ (range, 0.55-0.95). Table 3 also shows that the median Cronbach's alpha coefficients for MMHQQOL subscales from the first telephone interview was 0.85 (range, 0.79-0.92). Test-retest reliability for the two telephone administrations of the FISI was highly correlated $(r=0.75 ; P<0.0001)$. Table 4 illustrates mean scores with standard deviation for the subscales of the telephone-administered MMHQ-QOL and the possible ranges of these scores.

\section{DISCUSSION}

Development of a validated telephone-administered questionnaire to assess severity of fecal incontinence and its impact on quality of life is valuable because the prevalence of fecal incontinence is as high as 23 percent in multiparous females after vaginal delivery ${ }^{11}$ and 54 percent after primary anal sphincter repair. ${ }^{12}$ Because many females will have some improvement, if not complete resolution with time, having a tool to evaluate their symptoms with-
Table 4.

Mean Scores with Standard Deviation for the Subscales of the MMHQ-QOL

\begin{tabular}{lcc}
\hline MMHQ Scales & $\begin{array}{c}\text { Mean Score } \pm \\
\text { Standard Deviation }\end{array}$ & Range \\
\hline Impact & $61.9 \pm 31.2$ & $0-100$ \\
Role & $37.5 \pm 34.7$ & $0-100$ \\
Physical & $50.6 \pm 41.2$ & $0-100$ \\
Social & $42.9 \pm 40$ & $0-100$ \\
Relationships & $55.6 \pm 34.4$ & $0-100$ \\
Emotion & $42.1 \pm 36.2$ & $0-100$ \\
Sleep and energy & $36.9 \pm 36.6$ & $0-100$ \\
Severity & $51 \pm 31$ & $0-100$ \\
\hline
\end{tabular}

$\mathrm{MMHQ}=$ Modified Manchester Health Questionnaire.

out requiring a visit may result in better compliance to complete a study on fecal incontinence. Therefore, the MMHQ was developed as a telephoneadministered questionnaire to allow for more accurate assessment of prevalence and response to therapy by addressing both symptom severity and disease-specific quality of life.

When the self-administered FISI was compared with the telephone-administered FISI, slightly lower severity scores were obtained in the telephoneadministered questionnaire, but the difference (3.66 units) may not be clinically relevant (maximum score, 61). It was not possible to determine whether the self-administered or the telephone-administered scale was more accurate, because there is no "gold standard" instrument.

The telephone-administered MMHQ-QOL showed good convergent validity compared with the selfadministered FIQOL. The telephone-administered MMHQ also produced excellent test-retest reliability and internal consistency.

A limitation of this study is the relatively small sample. The participation rate was 71.4 percent of eligible patients. However, the sample was large enough to show that the psychometric properties of the scale are acceptable for research and clinical use.

\section{CONCLUSIONS}

This study demonstrated that the telephoneadministered MMHQ is a valid tool for assessing severity of fecal incontinence and its impact on quality of life in telephone-administered format. It meets standards for reliability and validity as well as testretest and internal consistency. Furthermore, this is the first study to assess test-retest reliability of FISI between written-to-telephone and telephone-to- 
telephone format. However, the responsiveness of the MMHQ to changes in clinical status such as those produced by treatment has yet to be determined in a longitudinal study.

\section{REFERENCES}

1. Johanson JF, Lafferty J. Epidemiology of fecal incontinence: the silent affliction. Am J Gastroenterol 1996;91: 33-6.

2. Nelson R, Norton N, Cautley E, Furner S. Communitybased prevalence of anal incontinence. JAMA 1995;274: 559-61.

3. Nelson R, Furner S, Jesudason V. Fecal incontinence in Wisconsin nursing homes: prevalence and associations. Dis Colon Rectum 1998;41:1226-9.

4. Vaizey CJ, Carapeti E, Cahill JA, Kamm MA. Prospective comparison of faecal incontinence grading systems. Gut 1999;44:77-80.

5. Jorge JM, Wexner SD. Etiology and management of fecal incontinence. Dis Colon Rectum 1993;36:77-97.

6. Pescatori M, Anastasio G, Bottini C, Mentasti A. New grading and scoring for anal incontinence: evaluation of 335 patients. Dis Colon Rectum 1992;35:482-7.
7. Rockwood TH, Church JM, Fleshman JW, et al. Patient and surgeon ranking of the severity of symptoms associated with fecal incontinence: the fecal incontinence severity index. Dis Colon Rectum 1999;42:1525-32.

8. Rockwood TH, Church JM, Fleshman JW, et al. Fecal incontinence quality of life scale: quality of life instrument for patients with fecal incontinence. Dis Colon Rectum 2000;43:9-16.

9. Bug GJ, Kiff ES, Hosker G. A new condition-specific health-related quality of life questionnaire for the assessment of women with anal incontinence. BJOG 2001;108:1057-67.

10. Badia Llach X, Castro Diaz D, Conejero Sugranes J. Validity of the King's Health questionnaire in the assessment of quality of life of patients with urinary incontinence. The King's Group. Med Clin (Barc) 2000;114: 647-52.

11. Sultan AH, Kamm MA, Hudson CN, Thomas JM, Bartram CI. Anal-sphincter disruption during vaginal delivery. N Engl J Med 1993;329:1905-11.

12. Zetterstrom J, Lopez A, Anzen B, Norman M, Holmstrom B, Mellgren A. Anal sphincter tears at vaginal delivery: risk factors and clinical outcome of primary repair. Obstet Gynecol 1999;94:21-8.

\section{APPENDIX \\ Modified Manchester Health Questionnaire ${ }^{1,2}$}

\section{SECTION A}

A1. How often do you have a strong desire to move your bowels which makes you rush to the toilet? ${ }^{3}$

A2. How often in the past month have you experienced any amount of accidental bowel leakage that consisted of solid stool? ${ }^{4}$

B1. Do you lose any solid stool when coughing or sneezing?

B2. Do you lose any solid stool when walking?

B3. Besides coughing, sneezing, and walking, do you lose any solid stool during the rest of the day or night?

A3. How often in the past month have you experienced any amount of accidental bowel leakage that consisted of liquid stool?

B4. When you leak stool, how often is it liquid or watery?

B5. Do you lose any liquid stool when coughing or sneezing?

B6. Do you lose any liquid stool when walking?

B7. Besides coughing, sneezing, and walking, do you lose any liquid stool during the rest of the day or night?

A4. How often in the past month have you experienced any amount of accidental bowel leakage that consisted of mucus?

A5. How often in the past month have you experienced any amount of accidental bowel leakage that consisted of gas?

B8. Do you lose any gas when coughing or sneezing?

B9. Do you lose any gas when walking? 
B10. Besides coughing, sneezing, and walking, do you lose any gas during the rest of the day or night?

B11. Do you have difficulty controlling gas?

\section{SECTION C: If the answers to A1, A2, A3, A4, and A5 are all "Never," skip this section.}

C1. How much do you think your bowel problem affects your life?

\begin{tabular}{|c|c|c|c|c|}
\hline $\begin{array}{c}1 \\
\text { Not at all }\end{array}$ & $\begin{array}{c}2 \\
\text { A little bit }\end{array}$ & $\begin{array}{c}3 \\
\text { Moderately }\end{array}$ & $\begin{array}{c}4 \\
\text { Quite a bit }\end{array}$ & $\begin{array}{c}\mathbf{5} \\
\text { Extremely }\end{array}$ \\
\hline
\end{tabular}

C2. How often do you move your bowels each day?
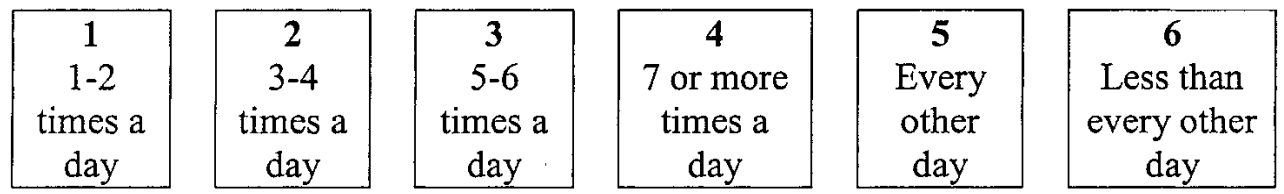

C3. Do you have difficulty wiping clean after you have moved your bowels?

C4. What percent of your bowel movements are hard or little balls?

C5. What percent of your bowel movements are loose or watery?

\section{Role limitations}

C6. Do you have a problem with your bowels that affects doing jobs within the home? C6a. If so, how often does it affect you?

C7. Do you have a problem with your bowels that affects your job, or your normal daily activities outside the home?

$\mathrm{C} 7 \mathrm{a}$. If so, how often does it affect you?

\section{Physical/social limitations}

C8. Do you have a problem with your bowels that affects your ability to travel? C8a. If so, how often does it affect you?

C9. Do you have a problem with your bowels that affects your physical activities (such as going for a walk, running, sport, gym, etc.)?

C9a. If so, how often does it affect you?

C10. Do you have a problem with your bowels that limits your social life? C10a. If so, how often, does it affect you?

C11. Do you have a problem with your bowels that limits your ability to see and visit friends? C11a. If so, how often does it affect you?

\section{Personal relationships}

C12. Do you have a problem with your bowels that affects your relationship with your partner? C12a. If yes, how often does it affect your relationship?

C13. Do you have a problem with your bowels that affects your family life? C13a. If so, how often does it affect your family life? 


\section{Emotions}

C14. Do you have a problem with your bowels that makes you feel depressed?

C14a. If yes, how often does it affect you?

C15. Do you have a problem with your bowels that makes you feel anxious or nervous? C15a. If yes, how often does it affect you?

C16. Do you have a problem with your bowels that makes you feel bad about yourself? C16a. If yes, how often does it affect you?

\section{Sleep/energy}

C17. Do you have a problem with your bowels that affects your sleep?

C17a. If so, how often does it affect your sleep?

C18. Do you have a problem with your bowels that makes you feel worn out and tired? C18a. If yes, how often does it affect you?

\section{Sexual Activity}

\section{For general audience, skip questions C19a to C19c.}

C19. Have you resumed sexual activity since delivery?

C19a. If "Yes," when did you resume sexual activity? _ _ weeks after delivery

C19b. If "No," why have you not resumed sexual activity?

\begin{tabular}{|c|c|c|}
\hline $\begin{array}{c}1 \\
\text { Not allowed by } \\
\text { clinician yet } \\
\text { SKIP TO C24 }\end{array}$ & $\begin{array}{c}\mathbf{2} \\
\text { Too tired } \\
\text { SKIP TO C24 }\end{array}$ & \begin{tabular}{l}
\multicolumn{3}{c}{ Too painful } \\
SKIP TO C24
\end{tabular} \\
\hline \multicolumn{3}{|c|}{$\begin{array}{l}8 \text { Other } \\
\text { Specify: }\end{array}$} \\
\hline
\end{tabular}

C20. Do you have a problem with your bowels that affects your sex life? C20a. If so, how often does it affect your sex life?

C21. Do you lose any gas during or after sexual activity?

C22. Do you lose any stool during or after sexual activity?

C23. Do you lose any urine during or after sexual activity?

\section{Lifestyle Adaptation}

C24. Do you wear pads to keep clean because of a problem with your bowels? C24a. If yes, how often do you wear pads?

$\mathrm{C} 25$. Are you careful about how much food you eat because of a problem with your bowels? C25a. If yes, how often are you careful about how much food you eat?

C26. Do you change your underclothes because they get dirty due to a problem with your bowels? C26a. If yes, how often do you change your underclothes for this reason?

C27. Do you worry about odor because of a problem with your bowels? C27a. If yes, how often do you worry about it? 
C28. Do you get embarrassed because of a problem with your bowels?

C28a. If yes, how often do you get embarrassed?

\section{Medical}

C29. Did you bring any of your bowel symptoms to the attention of your clinician?

C30. Have you received treatment for your bowel symptoms?

C30a. If "Yes," please specify:

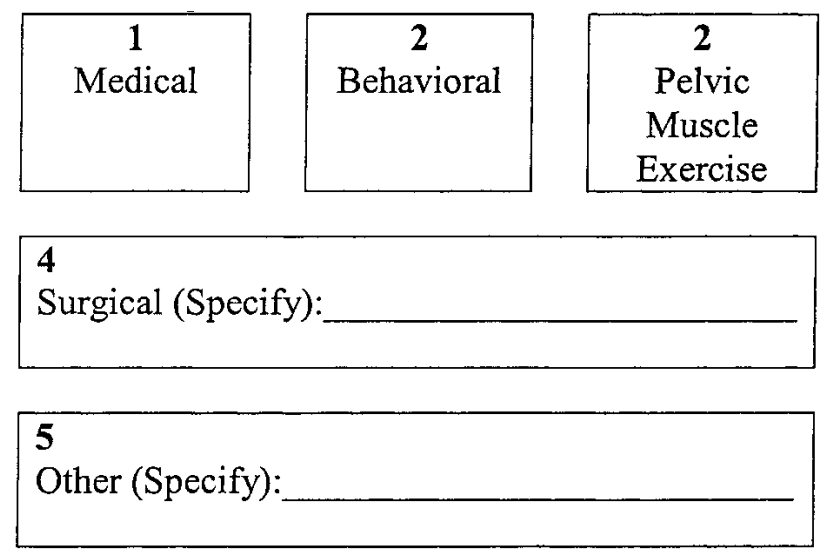

C31. Do you have any comments that are important to you which have not been covered?

${ }^{1}$ For an exact copy of the form used for telephone interviews and for scoring instructions, contact the corresponding author.

${ }^{2} A 2, A 3, A 4$, and A5 compose the FISI component of the questionnaire.

${ }^{3}$ The possible responses to questions A1, B1 to B11, C3, C6a, C7a, C8a, C9a, C10a, C11a, C12a, C13a, C14a, C15a, C16a, C18a, C20a, C21, C22, C23, C24a, C25a, C26a, C27a, and C28a are as follows:

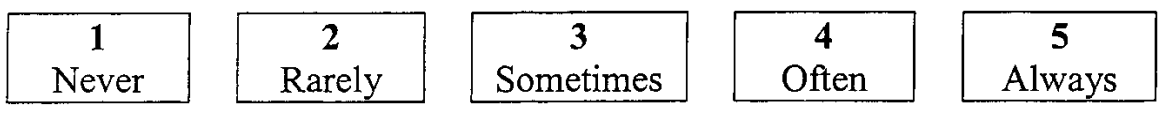

${ }^{4}$ The possible responses to questions A2, A3, A4, and A5 are as follows:
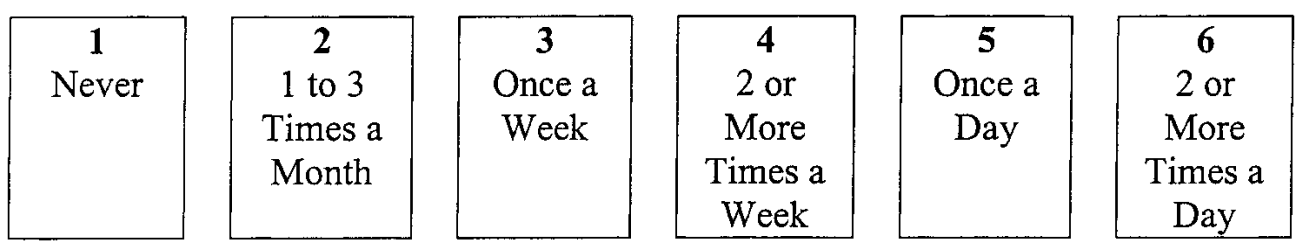

${ }^{5}$ The possible responses to questions $C 4$ and $C 5$ are as follows:
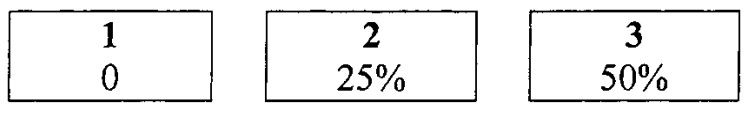

\section{Invited Commentary}

To the Editor-The article by Kwon et al., Validity and Reliability of the Modified Manchester Health Questionnaire, represents an important step in the

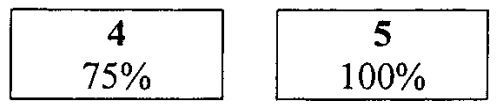

direction of developing measures for assessing quality of life (QOL) in patients with fecal incontinence (FI) by use of a standardized questionnaire administered in the telephone mode. There is a need for such a tool in conducting research regarding FI and the findings 
from this work demonstrate the feasibility of this approach, although other work in this area has not provided such optimistic findings. ${ }^{1}$

This article has several key strengths, especially the thought associated with instrumentation. The development of the Modified Manchester Health Questionnaire (MMHQ) combined with the use of the Fecal Incontinence Severity Index (FISI), and the Fecal Incontinence Quality of Life Questionnaire (FIQOL) indicates a sensitivity to two important issues: the dynamics associated with measurement between different modes of survey administration in the measurement of health related issues, ${ }^{2}$ and the usefulness of multiple operationalization. ${ }^{3,16,17}$ The findings indicate that it may be possible to administer QOL instrument(s) regarding FI in the telephone mode, which may ultimately lead to an instrument that can be used in both modes of administration, mail (or any form of self-administered questionnaires (SAQ)), and telephone.

The survey picture is not as positive, because it raises a fundamental problem in contemporary research: the failure of knowledge from one area of research (e.g., survey methodology) to be used in other areas (e.g., QOL assessment). Research such as this needs be grounded not just in knowledge about the assessments of QOL but also in survey methods.

The survey methodology literature has a great deal to say about the mode of administration. ${ }^{6,19}$ A couple of key areas where this literature applies to both the design and the interpretation of the findings from this research deserve comment. The basic models for mail vs. telephone administration of surveys range from rather simple but important models, ${ }^{8}$ to moderate complexity $^{9}$ or very complex models. ${ }^{10}$ These should serve as a starting point in the consideration of the survey methods for work such as this.

The authors recognize that the primary implications for this study are important in the research community because of nonresponse error that is, mail surveys generally tend to have lower response rates than the telephone. Thus, the telephone mode is primarily identified as a means of reducing nonresponse error. ${ }^{11,24-26}$ However, this reduction of nonresponse error comes with a price, the increased risk of measurement error. ${ }^{6,27}$ Measurement error is more of a problem in the telephone mode of administration than in other modes of survey administration, ${ }^{6,23,28}$ and, in general, the survey research community is starting to identify measurement error as greater concern in survey research than nonresponse error. ${ }^{17}$
The authors should be commended for recognizing that measurement error is a fundamental concern associated with their research. Their recognition of the implications associated with an interviewer asking a person about FI as opposed to checking a box on a SAQ has implications for not just measurement, but the psychometric properties of psychosocial constructs (MMHQ scales, e.g., role, physical, social, etc.) represents a fundamental strength of what they have done. But, the failure to design the study to address what is known about measurement error relative to mail vs. telephone administration presents significant barriers to the utility of the research that was performed. A large number of areas associated with measurement error could be discussed, but comments will be limited to three fundamental areas: items, response categories, and questionnaires.

The authors recognize that FI is potentially associated with social desirability bias in measurement between the mail and telephone modes; therefore, the content of the items is important. ${ }^{2}$ This recognition of social desirability bias is a key strength of their work, but other aspects beyond item content, such as response categories and questionnaire design, also must be considered to evaluate mode differences relative to the psychometric properties of an instrument. ${ }^{18}$

The authors indicate a fundamental issue was deciding whether to use the Manchester Health Questionnaire (MHQ) or the FIQOL as the "base" for developing the MMHQ. The selection of the MHQ was based on complexity of the response categories in the FIQOL (use of different types of response scales). Although the reasoning was sound, knowledge about response formation in survey methods ${ }^{19,32,33}$ and the error associated with items and response scales ${ }^{22,35}$ especially when considering differences between the mail and telephone mode, ${ }^{10}$ or in consideration of mixing data collected from using data from different modes in a study, suggests that using different types of response scales is probably the better option. ${ }^{6}$

The literature about questionnaires ${ }^{6,30}$ is large and the findings are anything but conclusive. ${ }^{11,25}$ Measurement error is not just associated with the wording of an item (e.g., social desirability) and the response alternatives used (e.g., ratings $v s$. frequency), but is associated with the instrument itself. ${ }^{6,20,30}$ Investigation into mode differences needs to evaluate the effects caused by question-order effects, norm of reciprocity, social desirability, satisfying, as well as other factors. ${ }^{12,27,30,32,36}$

This article is important for two reasons. First, it is a 
positive step toward developing an instrument for the assessment of QOL in FI using the telephone mode. The results indicate the feasibility of developing such a measure. Second, it illustrates the difficulties and problems associated with this type of research. The lack of the integration of knowledge and methods associated with mode effects research in survey methods limits the usefulness of the findings of the research. Whether the MMHQ is a viable instrument for assessing QOL in FI in the telephone mode remains to be established.

\section{REFERENCES}

1. Rockwood TH, Kane RL, Lowry A. Mode of administration considerations in the development of condition specific quality of life scales. In: 7th Health Surveys Conference. Williamsburg, VA: National Center for Health Statistics, 1999.

2. Fowler ,Jr FJ, Roman AM, Di ZX. Mode effects in a survey of medicare prostate surgery patients. Public Opin Q 1998;62:29-46.

3. Blalock HM. Measurement in the social sciences: theories and strategies. Chicago: Aldine Publishing Co., 1974:464.

4. Campbell DT, Overman ES. Methodology and epistemology for social science: selected papers. Chicago: University of Chicago Press, 1988:609.

5. Campbell DT, Russo MJ. Social measurement. Thousand Oaks: Sage Publications, 2001:509.

6. Dillman DA. Mail and electronic surveys: the tailored design method. 2nd ed. New York: Wiley, 1999.

7. Dillman DA. Mail and telephone surveys: the total design method. New York: Wiley, 1978:325.

8. Schwarz N, et al. The impact of administration mode on response effects in survey measurement. Appl Cogn Psychol 1991;5:193-212.

9. Dillman DA, Sangster, RL, Tarnai, J, Rockwood, TH. Understanding differences in people's answers to telephone and mail surveys. In: Braverman, MT and Slater $\mathrm{JK}$, eds. Advances in survey research. San Francisco: Jossey-Bass, 1996;70:110.

10. Rockwood TH, Sangster RL, Dillman DA. The effect of response categories on questionnaire answers: context and mode effects. Sociol Methods Res 1997;26:118-40.

11. Groves RM, Dillman, DA, Etlinge, JL, Little, RJA. Survey nonresponse. Wiley series in survey methodology. New York: Wiley, 2002:500.

12. Groves RM, Beimer, PP, Lyberg, LE, Massey, JT, Nichools, WLI, Waksberg, J. Telephone survey methodology. New York: Wiley, 1988:581.

13. Groves RM. Survey errors and survey costs. Wiley series in probability and mathematical statistics. New York: Wiley, 1989:590.
14. Groves RM, Couper M. Nonresponse in household interview surveys. Wiley series in probability and statistics. Survey methodology section. New York: Wiley, 1998:344.

15. Biemer PP, Groves, RM, Lyberg, LE, Mathiowitz, NA, Sudman, S. Measurement errors in surveys. New York: Wiley, 1991:760.

16. Lyberg L. Survey measurement and process quality. Wiley series in probability and statistics. Applied probability and statistics. New York: Wiley, 1997:777.

17. Martin E. Presidential address: unfinished business. Public Opin 2004;68:439-50.

18. Schwarz N, Sudman, S. Context effects in social and psychological research. New York: Springer-Verlag, 1992:353.

19. Tourangeau R, Rips LJ, Rasinski K. The psychology of survey response. Cambridge: Cambridge University Press, 2000.

20. Sudman S, Bradburn NM, Schwarz N. Thinking about answers: the application of cognitive processes to survey methodology. San Francisco: Jossey-Bass, 1996:304.

21. Sirken MG. Cognition and survey research. Wiley series in probability and statistics. Survey methodology section. New York: Wiley, 1999:395.

22. Schwarz N, Bless H, Bohner G, Harlacher U, Kellenbenz M. Response scales as frames of reference: the impact of frequency range on diagnostic judgments. Appl Cogn Psychol 1991;5:37-49.

23. Schwarz N, Knauper B, Hippler H-J, Noelle-Neumann E, Clark L. Rating scales: numeric values may change the meaning of scale labels. Public Opin Q 1991;55: 570-82.

24. Schwarz N, Sudman S. Answering questions: methodology for determining cognitive and communicative processes in survey research. San Francisco: JosseyBass, 1996:469.

Todd Rockwood, Ph.D. Minneapolis, Minnesota

\section{The Authors Reply}

To the Editor-We thank the commentator for his recognition that our study "is a positive step toward developing an instrument for the assessment of QOL in FI using the telephone mode." The goal of being able to accurately assess the impact of FI on quality of life and assess changes in quality of life with time is important because, in comparison to postal surveys, telephone surveys reduce nonresponse (attrition) and makes data collection less costly. We are grateful to the commentator for making readers aware that there is a body of research on survey methodology that can 
enrich efforts such as ours to develop a telephone survey.

We would like to reply to two points raised in the commentary:

As the commentary acknowledges, we decided to use the Manchester Health Questionnaire ${ }^{1}$ (MHQ) rather than the Fecal Incontinence Quality of Life Scale $^{2}$ (FIQOL) as the basis for developing our telephone questionnaire because the MHQ has a response format that is easily adopted to telephone surveys (e.g., "Does your bowel problem affect your job, or your normal daily activities outside the home? Never, Rarely, Sometimes, Often, or Always?), whereas the FIQOL uses four different response scales. Our experience in constructing questionnaire is that patients may become confused when they have to be reoriented to new response scales, and that this problem is significantly greater for telephone surveys than for paper questionnaires.

The commentary states, "Measurement error is not just associated with the wording of an item (e.g., social desirability) and the response alternatives used (e.g., ratings $v s$. frequency), but is associated with the instrument itself." We recognized this and chose an instrument with a more easily adapted response format only after assuring ourselves that the validity and reliability of the MHQ and the FIQOL were comparable. Very similar approaches were used by the authors of these two questionnaires to assess their reliability (test-retest, internal consistency) and validity [comprehensiveness and understandability to both clinicians and patients, correlation with the generic SF36 quality of life scale, and ability to discriminate incontinent patients from controls (FIQOL) or patients with mild incontinence from those with more severe incontinence (MHQ)]; the published test statistics for the two scales were comparable.

We believe that our study does more than show that it is feasible to develop a telephone survey to assess the severity of fecal incontinence and the impact of fecal incontinence on quality of life. We believe that our study shows that the Modified Manchester Health Questionnaire has adequate validity, reliability, and agreement with published paper questionnaires to be used in clinical trials and survey research.

\section{REFERENCES}

1. Bug GJ, Kiff ES, Hosker G. A new condition-specific health-related quality of life questionnaire for the assessment of women with anal incontinence. BJOG 2001;108:1057-67.

2. Rockwood TH, Church JM, Fleshman JW, et al. Fecal Incontinence Quality of Life Scale: quality of life instrument for patients with fecal incontinence. Dis Colon Rectum 2000;43:9-16.

Soo Kwon, M.D.

Anthony G. Visco, M.D. William E. Whitehead, Ph.D. Chapel Hill, North Carolina

Mary P. Fitzgerald, M.D. Maywood, Illinois

Wen Ye, M.S. Ann Arbor, Michigan 